Supplement of Weather Clim. Dynam., 1, 349-371, 2020

https://doi.org/10.5194/wcd-1-349-2020-supplement

Weather and

(C) Author(s) 2020. This work is distributed under the Creative Commons Attribution 4.0 License.

(c) (i)

$\mathrm{L}$

Supplement of

\title{
The American monsoon system in HadGEM3 and UKESM1
}

Jorge L. García-Franco et al.

Correspondence to: Jorge L. García-Franco (jorge.garcia-franco@physics.ox.ac.uk)

The copyright of individual parts of the supplement might differ from the CC BY 4.0 License. 
Table S1. Summary of the CMIP6 simulations in this study. For each simulation the acronym used hereafter, the experiment and the horizontal resolution are shown. The first 100 years of the piControl simulations are used and for historical experiments the period 1979-2014 is used.

\begin{tabular}{|c|c|c|c|c|}
\hline Model & Experiment & Resolution & Acronym & Reference \\
\hline $\begin{array}{l}\text { Hadley Centre Global Environment } \\
\text { Model version } 3 \text { (HadGEM3) }\end{array}$ & Pre-industrial control & N96 $1.875^{\circ} \times 1.25^{\circ}$ & GC3.1 N96-pi & $\begin{array}{l}\text { (Menary et al., 2018; } \\
\text { Ridley et al., 2018) }\end{array}$ \\
\hline HadGEM3 & Pre-industrial control & $\mathrm{N} 2160.83^{\circ} \times 0.56^{\circ}$ & GC3 N216-pi & $\begin{array}{l}\text { (Menary et al., 2018; } \\
\text { Ridley et al., 2019c) }\end{array}$ \\
\hline HadGEM3 & Historical & $\mathrm{N} 961.875^{\circ} \times 1.25^{\circ}$ & GC3-hist & $\begin{array}{l}\text { (Andrews et al., 2020; } \\
\text { Ridley et al., 2019b) }\end{array}$ \\
\hline HadGEM3 & $\begin{array}{l}\text { Atmospheric Model Inter- } \\
\text { comparison (AMIP) }\end{array}$ & $\mathrm{N} 961.875^{\circ} \times 1.25^{\circ}$ & GC3-AMIP & (Ridley et al., 2019a) \\
\hline $\begin{array}{l}\text { United Kingdom Earth System } \\
\text { Model version } 1 \text { (UKESM1) }\end{array}$ & Pre-industrial control & $1.875^{\circ} \times 1.25^{\circ}$ & UKESM-pi & (Tang et al., 2019b) \\
\hline UKESM1 & Historical & $1.875^{\circ} \times 1.25^{\circ}$ & UKESM-hist & (Tang et al., 2019a) \\
\hline
\end{tabular}


Table S2. Root-mean square error (RMSE) and pattern correlation coefficients (PCC) for each season and each model experiment. Near surface air temperature $(t 2 m)$, wind components $(u$ and $v)$ and mean-sea level pressure $(m s l p)$ are assessed against ERA-5 and precipitation (pr) against TRMM.

\begin{tabular}{|c|c|c|c|c|c|c|c|c|c|}
\hline Variable & Model experiment & $\begin{array}{l}\text { DJF } \\
\text { RMSE }\end{array}$ & $\begin{array}{l}\text { DJF } \\
\text { PCC }\end{array}$ & $\begin{array}{l}\text { MAM } \\
\text { RMSE }\end{array}$ & $\begin{array}{l}\text { MAM } \\
\text { PCC }\end{array}$ & $\begin{array}{l}\text { JJA } \\
\text { RMSE }\end{array}$ & $\begin{array}{l}\text { JJA } \\
\text { PCC }\end{array}$ & $\begin{array}{l}\text { SON } \\
\text { RMSE }\end{array}$ & $\begin{array}{l}\text { SON } \\
\text { PCC } \\
\end{array}$ \\
\hline $\mathrm{t} 2 \mathrm{~m}$ & GC3 N96 & 1.28 & 0.98 & 1.3 & 0.96 & 1.38 & 0.96 & 1.31 & 0.96 \\
\hline $\mathrm{t} 2 \mathrm{~m}$ & GC3 N216 & 1.05 & 0.99 & 1.07 & 0.98 & 1.02 & 0.98 & 0.98 & 0.98 \\
\hline $\mathrm{t} 2 \mathrm{~m}$ & GC3 Hist & 2.06 & 0.94 & 1.75 & 0.93 & 1.73 & 0.94 & 2.05 & 0.92 \\
\hline $\mathrm{t} 2 \mathrm{~m}$ & UKESM-hist & 2.03 & 0.94 & 1.77 & 0.93 & 1.8 & 0.94 & 2.0 & 0.93 \\
\hline $\mathrm{t} 2 \mathrm{~m}$ & GC3 AMIP & 1.17 & 0.98 & 1.12 & 0.97 & 1.2 & 0.97 & 1.2 & 0.97 \\
\hline $\mathrm{u}$ & GC3 N96 & 0.78 & 0.99 & 0.59 & 0.99 & 0.9 & 0.98 & 0.87 & 0.98 \\
\hline $\mathrm{u}$ & GC3 N216 & 0.78 & 0.99 & 0.59 & 0.99 & 0.9 & 0.98 & 0.87 & 0.98 \\
\hline $\mathrm{u}$ & GC3 Hist & 1.02 & 0.98 & 1.04 & 0.97 & 0.92 & 0.98 & 0.84 & 0.98 \\
\hline $\mathrm{u}$ & UKESM-hist & 1.04 & 0.98 & 1.01 & 0.97 & 0.91 & 0.98 & 0.82 & 0.98 \\
\hline $\mathrm{u}$ & GC3 AMIP & 0.96 & 0.98 & 0.77 & 0.99 & 1.18 & 0.97 & 1.09 & 0.96 \\
\hline $\mathrm{v}$ & GC3 N96 & 0.75 & 0.93 & 0.66 & 0.93 & 0.65 & 0.95 & 0.59 & 0.94 \\
\hline $\mathrm{v}$ & GC3 N216 & 0.6 & 0.96 & 0.5 & 0.95 & 0.57 & 0.96 & 0.54 & 0.94 \\
\hline $\mathrm{v}$ & GC3 Hist & 0.76 & 0.94 & 0.72 & 0.92 & 0.66 & 0.95 & 0.59 & 0.94 \\
\hline $\mathrm{v}$ & UKESM-hist & 0.75 & 0.93 & 0.69 & 0.92 & 0.65 & 0.95 & 0.6 & 0.93 \\
\hline $\mathrm{v}$ & GC3 AMIP & 0.67 & 0.95 & 0.52 & 0.95 & 0.68 & 0.94 & 0.61 & 0.93 \\
\hline mslp & GC3 N96 & 1.33 & 0.96 & 1.03 & 0.97 & 1.15 & 0.96 & 0.95 & 0.97 \\
\hline mslp & GC3 N216 & 1.11 & 0.97 & 0.9 & 0.97 & 1.1 & 0.96 & 0.89 & 0.97 \\
\hline mslp & GC3 Hist & 1.31 & 0.97 & 1.12 & 0.96 & 1.08 & 0.96 & 0.94 & 0.97 \\
\hline mslp & UKESM-hist & 1.4 & 0.97 & 1.15 & 0.96 & 1.14 & 0.95 & 0.99 & 0.97 \\
\hline mslp & GC3 AMIP & 1.15 & 0.97 & 0.87 & 0.97 & 1.09 & 0.96 & 0.93 & 0.97 \\
\hline $\mathrm{pr}$ & GC3 N96 & 2.02 & 0.79 & 2.24 & 0.71 & 1.62 & 0.9 & 1.69 & 0.86 \\
\hline pr & GC3 N216 & 1.58 & 0.88 & 1.72 & 0.85 & 1.4 & 0.93 & 1.57 & 0.89 \\
\hline pr & GC3 Hist & 2.05 & 0.78 & 2.49 & 0.64 & 1.69 & 0.88 & 1.69 & 0.86 \\
\hline pr & UKESM-hist & 1.96 & 0.8 & 2.39 & 0.66 & 1.71 & 0.88 & 1.62 & 0.87 \\
\hline $\mathrm{pr}$ & GC3 AMIP & 1.42 & 0.9 & 1.61 & 0.88 & 1.95 & 0.88 & 1.8 & 0.88 \\
\hline
\end{tabular}



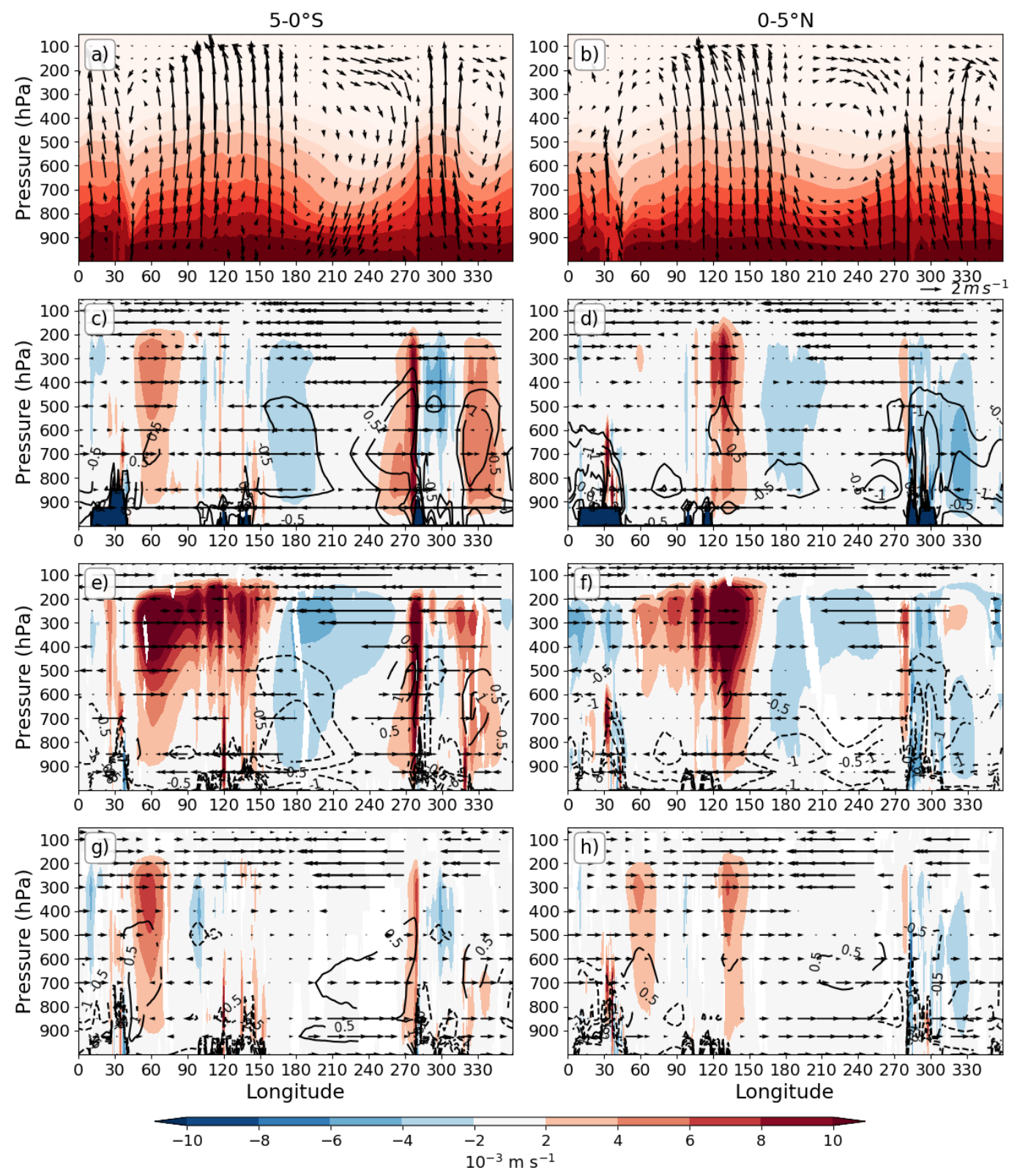

Figure S1. Longitude-pressure level plots of the mean DJF ( $a, b)$ specific humidity (color contours) and zonal and vertical velocities (vectors) in ERA5. (a) is latitudinally averaged in $5-0^{\circ} \mathrm{S}$ and (b) in $0-5^{\circ} \mathrm{N}$. (c, d, e, f, g, h) show the bias in vertical velocity (color-contours), zonal wind (vectors) and specific humidity (line contours). Biases are shown for (c, d) UKESM1-historical, (e, f) GC3.1 N96-pi and (g, h) GC3.1 N216-pi. Only biases statistically significant to the $95 \%$ confidence level are shown, according to a Welch t-test between model and ERA5 data for all fields. 

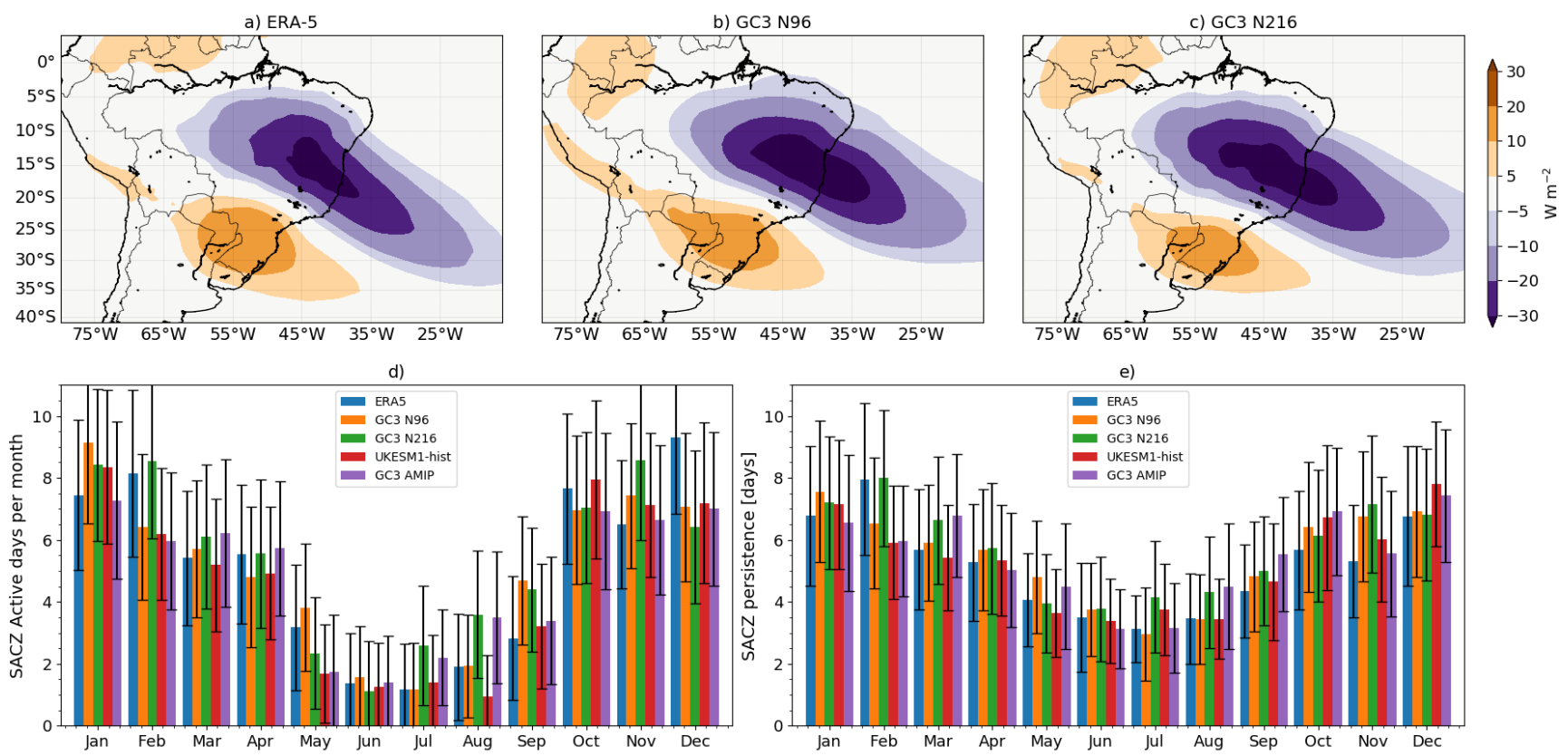

Figure S2. (a, b, c) OLR anomalies during active South Atlantic Convergence Zone (SACZ) events. (d, e) Frequency of active SACZ days and length of active SACZ events in reanalysis and model data, the standard deviation is shown as the error bar. The SACZ active days are constructed by first computing the first EOF of the monthly-mean deseasonalized OLR and then the daily OLR, previously filtered to remove periods higher than 99 days, is projected on the EOF pattern to produce a time-series of pseudo-principal components. Active SACZ days are found when this time-series of pseudo-PCs is greater than 1, and the persistence is measured as the number of continous days where the time-series is greater than 1 . 
ERA-5 djf El Nino Anomaly
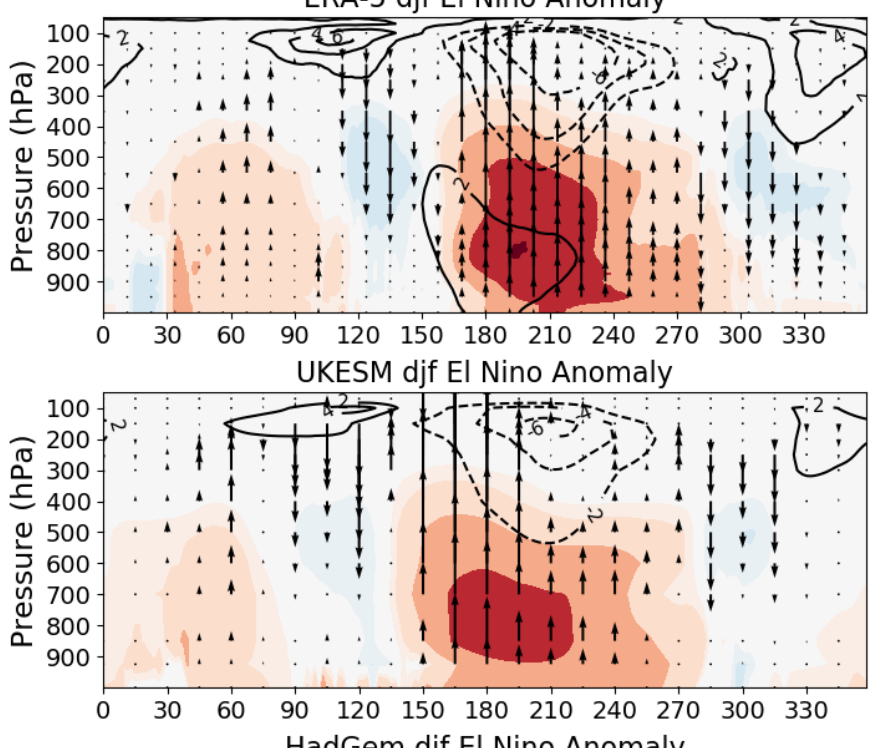
HadGem djf El Nino Anomaly

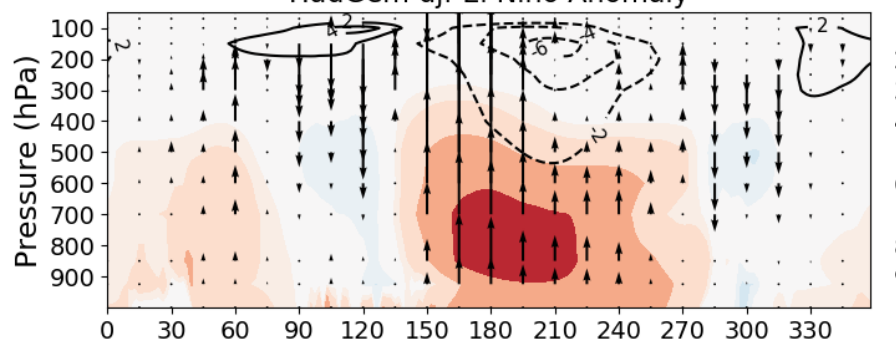

ERA-5 djf La Nina anomaly
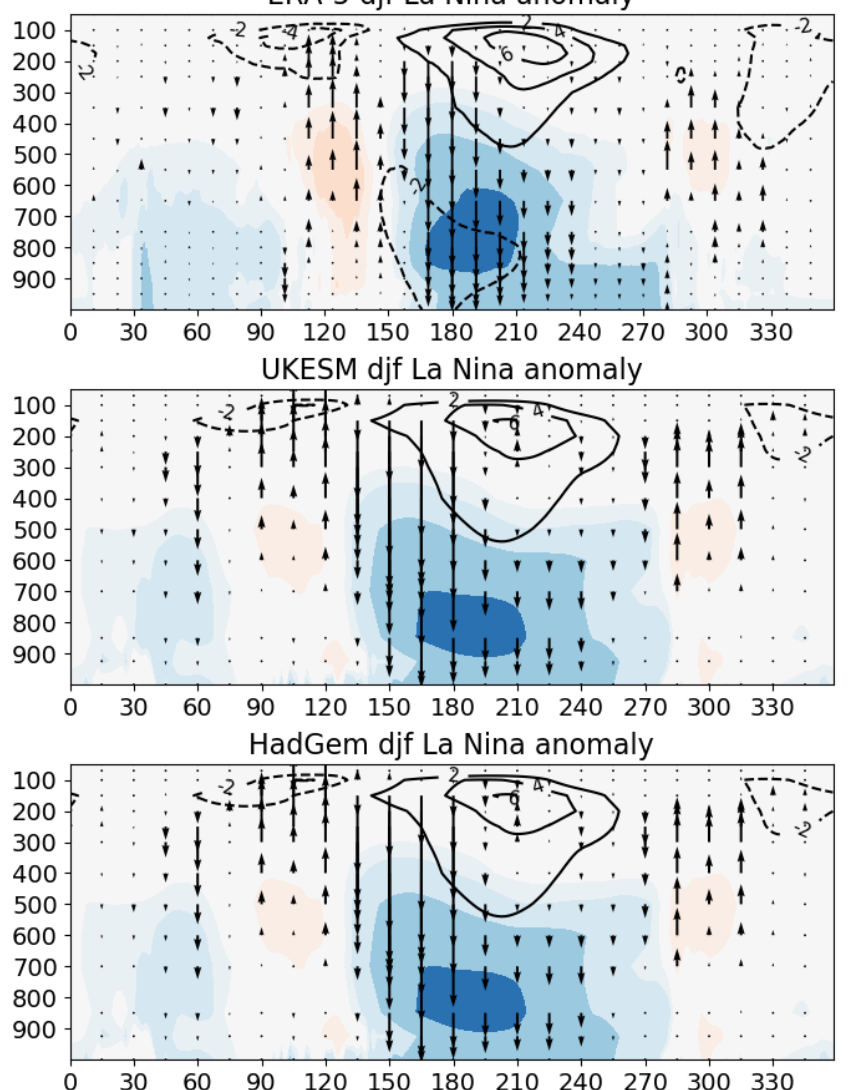

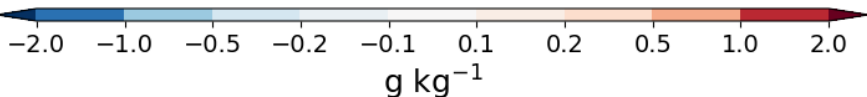

Figure S3. DJF Longitude-height Walker circulation anomalies of specific humidity (colour-contours), $\omega$ (vectors) and zonal wind (linecontours) during El Niño events (left) and La Niña events (right). Results are shown for ERA-5 (upper), UKESM-pi (middle) and HadGEM3 piControl (lower). 

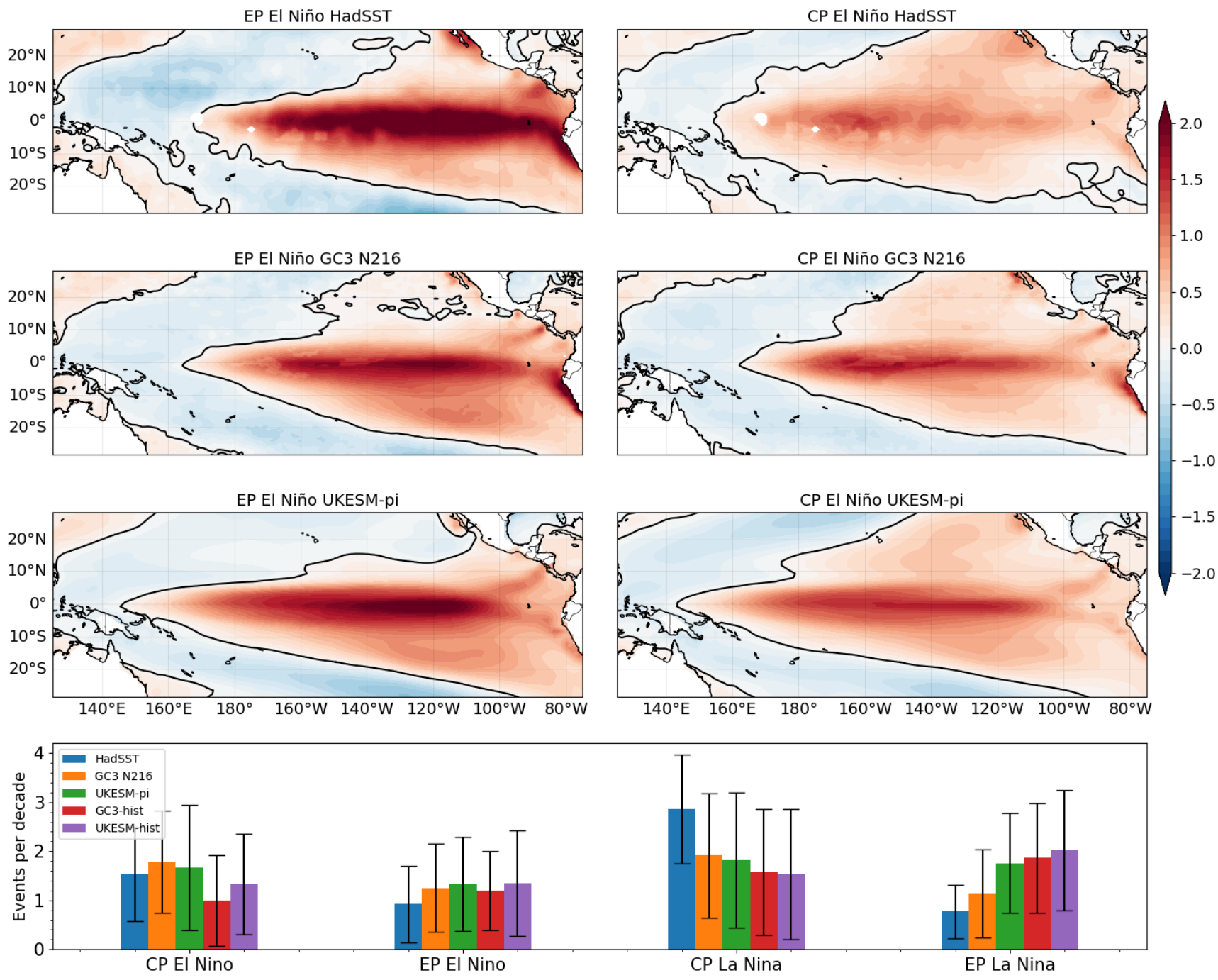

Figure S4. SST anomalies [K] for East Pacific (EP) and Central Pacific El Niño events in HadSST, GC3 N216 and UKESM piControl. EP (CP) events were defined where the E-index (C-index) was greater than 1. In the bottom panel, the frequency of events per decade (with standard deviation as error bar) is shown for HadSST and the simulations used in this study. The E-index is computed from $(P C 1-P C 2) / \sqrt{2}$ and the $\mathrm{C}$-index from $(P C 1+P C 2) / \sqrt{(2)}$. 